\title{
Enfermedad de neuro-Behçet con paquimeningitis en una niña
} Neuro-Behçet disease presented with pachymeningitis in a child

\author{
Dra. Gülsüm Alkana, Dra. Ayşe Kartal, Profesora asociadab, Dra. Melike Emiroğlu, Profesora asociadac y \\ Dr. Yahya Paksoy, Profesor ${ }^{d}$
}

\begin{abstract}
RESUMEN
La enfermedad de Behçet (EB) es un trastorno de vasculitis sistémica poco frecuente, de etiología desconocida, que se caracteriza por la presencia de aftas bucales, úlceras genitales y uveítis recurrentes. Afecta los sistemas nerviosos central y periférico; raramente se produce durantela niñez. La meningitis aséptica aguda aislada es muy poco frecuente. En este artículo, se describe el caso de una paciente de 14 años con diagnóstico de enfermedad de Behçet con afectación neurológica (neuroBehçet). La paciente tenía cefalea aguda, diplopia, papiledema e irritación meníngea. Tenía antecedentes de úlceras bucales recurrentes. Las imágenes por resonancia magnética de cerebro revelaron paquimeningitis. Los hallazgos en el líquido cefalorraquídeo fueron pleocitosis y aumento de la presión. Pese al tratamiento médico, sus síntomas no se resolvieron. No se detectó uveítis y la prueba de patergia fue negativa. El alelo HLA-B51 fue positivo. Se consideró que los hallazgos apuntaban a la poco frecuente enfermedad de Behçet con afectación neurológica. La paciente mejoró drásticamente luego del tratamiento con corticoesteroides. En el diagnóstico diferencial de meningitis, se debe considerar la EB, a menos que se demuestre la presencia de un agente infeccioso. Hasta donde sabemos, anteriormente no se había descrito un caso de paquimeningitis con neuro-Behçet en la población pediátrica. Palabras clave: síndrome de Behçet, meningitis aséptica, niños.
\end{abstract}

http: / / dx.doi.org/ 10.5546/ aap.2019.e644

Texto completo en inglés:

http: / / dx.doi.org/10.5546/ aap.2019.eng.e644

Cómo citar: Alkan G, Kartal A, Emiroglu M, Paksoy Y. Enfermedad de neuro-Behçet con paquimeningitis en una niña. Arch Argent Pediatr 2019;117(6):e644-e647.

a. Hospital de Formación e Investigación de Malatya, Departamento de Enfermedades Infecciosas Pediátricas, Malatya, Turquía.

b. Facultad de Medicina de Selçuk Üniversitesi, Departamento de Neurología Pediátrica, Konya, Turquía.

c. Facultad de Medicina de Selçuk Üniversitesi, Departamento de Enfermedades Infecciosas Pediátricas, Konya, Turquía.

d. Facultad de Medicina de Selçuk Üniversitesi, Departamento de Radiología, Konya, Turquía.

Correspondencia:

Dra. Gülsüm Alkan: galkan-85@hotmail.com

Financiamiento: Ninguno.

Conflicto de intereses: Ninguno que declarar.

Recibido: 18-11-2018

Aceptado: 6-6-2019

\section{INTRODUCCIÓN}

La enfermedad de Behçet (EB) es un trastorno inflamatorio crónico y recurrente que se caracteriza por la presencia de aftas bucales y úlceras genitales recurrentes, y diversas manifestaciones sistémicas (lesiones oculares, cutáneas y vasculares, enfermedades neurológicas, artritis, úlceras intestinales). La lesión patológica preexistente es una vasculitis oclusiva en arteriolas y venas. ${ }^{1}$ Esta enfermedad es más frecuente en Turquía (80-370,0 cada 100 000) y en otros países de Medio Oriente. La EB es poco frecuente en niños y se la clasifica vasculitis de vasos variables. ${ }^{2}$ El espectro clínico es heterogéneo. Las úlceras bucales y la fiebre idiopática son frecuentes al inicio de la enfermedad. En la actualidad, no hay pruebas o biomarcadores patognomónicos de EB reconocidos universalmente. Para el diagnóstico de EB en la población adulta es necesario determinar la presencia de dos de las manifestaciones clínicas, además de aftas bucales recurrentes, aftas genitales recurrentes, lesiones oftalmológicas (uveítis o vasculitis retiniana), lesiones dermatológicas (eritema nudoso, pseudofoliculitis, lesiones papulopustulosas, nódulos acneiformes) y prueba de patergia positiva de manera concomitante. ${ }^{1,3}$ Los niños suelen tener menos síntomas, y lleva tiempo llegar al diagnóstico. En pediatría, se utilizan 2 criterios diagnósticos: el criterio del International Study Group (ISG) (grupo internacional de estudio), con una especificidad del $96 \%$ y una sensibilidad del $91 \%$, y los criterios de Mason y Barnes, con una especificidad del $84 \%$ y una sensibilidad del $86 \%$. Si bien estas pruebas no fueron validadas en la población pediátrica, se encuentran en uso. ${ }^{3}$

Las úlceras bucales recurrentes son la manifestación clínica más frecuente en los niños. Del $20 \%$ al $40 \%$ de los niños con EB presenta algún compromiso articular, por lo general, artralgia en algunas articulaciones. La prueba de patergia no es un criterio para el diagnóstico de la EB en la población pediátrica. De ser necesario, se puede utilizar la prueba de patergia en la 
población pediátrica como criterio diagnóstico; una forma indirecta de saber si el resultado es positivo es contar con antecedentes de aparición de pápulas y pústulas en zonas que han sufrido algún microtraumatismo. La presencia del alelo HLA-B51 se asocia con una predisposición a la enfermedad. La EB suele ser mucho más grave en estos pacientes. ${ }^{4,5}$

\section{A PROPÓSITO DE UN CASO}

Se hospitalizó a una paciente de 14 años con cefalea y diplopia de tres días de evolución sin fiebre ni náuseas. Durante cinco días, la cefalea se localizó alrededor del cuello. Tenía antecedentes de úlceras bucales recurrentes durante dos años. Más allá de eso, sus antecedentes médicos no presentaban particularidades. Parecía estar alerta. Los signos vitales iniciales estaban dentro de los límites normales: temperatura corporal de $36,6{ }^{\circ} \mathrm{C}$; frecuencia cardíaca de 75 latidos / min; presión arterial de 100/60 mmHg; y frecuencia respiratoria de $20 / \mathrm{min}$. Su peso era de $47 \mathrm{~kg}$ (percentilo 10-25) y su estatura, $152 \mathrm{~cm}$ (percentilo 3-10). Durante el examen físico de ingreso, los signos de papiledema bilateral e irritación meníngea eran positivos, y no había particularidades en los resultados de los exámenes del resto de los sistemas. En la resonancia magnética (RM) de cerebro, se observó realce paquimeníngeo con realce leptomeníngeo con contraste (Figura 1a).

En la punción lumbar, se observó presión intracraneal elevada $\left(640 \mathrm{mmH}_{2} \mathrm{O}\right)$. El análisis de líquido cefalorraquídeo (LCR) reveló 330 células / $\mathrm{mm}^{3}$ con linfocitos; las concentraciones de proteínas, glucosa y cloruro eran de $161 \mathrm{mg} /$ dl, $63 \mathrm{mg} / \mathrm{dl}$ y $129 \mathrm{mmol} / \mathrm{l}$, respectivamente. Los datos primarios de laboratorio fueron los siguientes: recuento de leucocitos $9100 / \mathrm{mm}^{3}$, neutrófilos $75 \%$; hemoglobina $15 \mathrm{~g} / \mathrm{dl}$; plaquetas $396000 / \mathrm{mm}^{3}$; velocidad de eritrosedimentación $7 \mathrm{~mm} / \mathrm{h}$ y proteína C-reactiva $0,1 \mathrm{mg} / \mathrm{dl}$. El resultado del análisis bioquímico sérico fue normal. En función de estos resultados clínicos y de laboratorio, a la paciente se le diagnóstico meningitis aséptica aguda. La paciente recibió ceftriaxona y acetazolamida. Los resultados de la reacción en cadena de la polimerasa (PCR) en LCR para el virus de herpes simple, Streptococcus pneumoniae, Neisseria meningitidis, Haemophilus influenzae y Enterovirus fueron negativos. El cultivo de LCR fue negativo. La serología viral en suero no presentaba particularidades. Dado que no hubo mejoras en los resultados clínicos, se repitió la punción lumbar al cabo de una semana. El LCR seguía teniendo presión elevada, 495 células $/ \mathrm{mm}^{3}$ con predominio linfocítico, proteína $180 \mathrm{mg} / \mathrm{dl}$ y glucosa $80 \mathrm{mg} / \mathrm{dl}$. La PCR de LCF para el diagnóstico de tuberculosis, la tinción para bacilos acidorresistentes y la prueba de aglutinación y LCR para Brucella fueron negativos. Los resultados de las pruebas serológicas para enfermedad de Lyme, Rickettsia y Brucella en sangre fueron negativos. El resultado de la prueba de la tuberculina cutánea fue negativo. La radiografía de tórax y la ecografía abdominal fueron normales. En el LCR no se detectaron anticuerpos de neuromielitis

FIGURA 1. RM de cerebro. (1a) En las imágenes coronales ponderadas en T1 posgadolinio, se observa realce paquimeníngeo. (1b) Un mes después del tratamiento con corticoesteroides, en la RM de seguimiento, se observó la regresión casi completa del realce paquimeningeo.

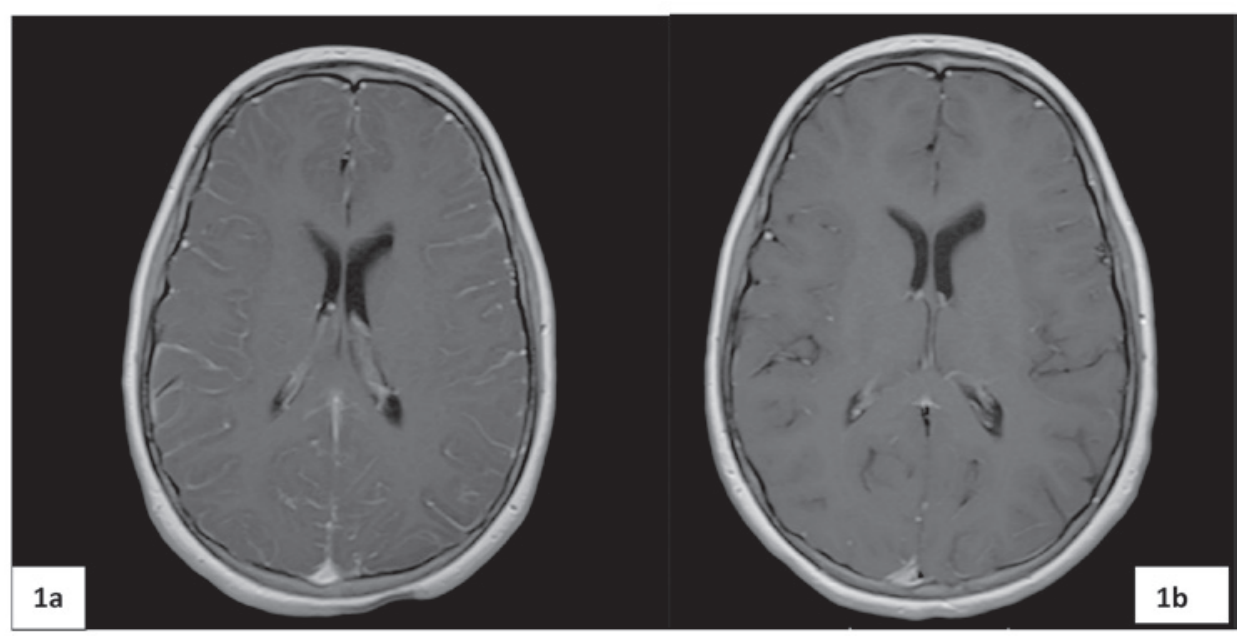


óptica ni bandas oligoclonales. Las pruebas de detección inmunológica fueron normales. Los marcadores de trastornos autoinmunitarios y del tejido conjuntivo (es decir, anticuerpos antinucleares, anti-ADN bicatenario, C3, C4, Coombs, anticuerpos anticardiolipina, hormona estimulante de la tiroides y T4 libre) fueron negativos. Los análisis de laboratorio confirmaron la ausencia de sarcoidosis. Al analizar más profundamente los antecedentes de la paciente en relación con la EB, ella recordó haber recibido el diagnóstico de artritis cinco años antes. En los antecedentes familiares, no se registró ninguna enfermedad relevante. No se halló uveítis en el examen oftalmológico. La prueba de patergia fue negativa. La venografía por RM fue normal. Se confirmó la presencia del alelo HLA-B51. Los resultados clínicos y de laboratorio anormales coincidían con el diagnóstico de neuro-Behçet no parenquimatosa. La paciente recibió metilprednisolona en dosis altas por vía intravenosa durante 5 días, seguida de prednisolona por vía oral $(60 \mathrm{mg})$. En el día dos de tratamiento, la cefalea y la diplopia mejoraron gradualmente. Una semana después el papiledema desapareció por completo. En la RM de cerebro de seguimiento, se observó la regresión casi completa del realce leptomeníngeo (Figura 1b). Los parámetros del LCR mejoraron a 33 células $/ \mathrm{mm}^{3}$ con predominio linfocítico y una concentración de proteínas de $74 \mathrm{mg} / \mathrm{dl}$; la presión intracraneal era normal. Se disminuyó gradualmente la dosis de prednisolona y se interrumpió el tratamiento un mes más tarde. Durante 6 meses de seguimiento, la paciente no manifestó ningún síntoma.

\section{DISCUSIÓN}

El compromiso del sistema nervioso central por la enfermedad se conoce como neuro-Behçet y presenta manifestaciones neurológicas variables. El espectro clínico incluye la demencia, síntomas psiquiátricos, parálisis de pares craneales, ataxia cerebelosa y signos de la vía piramidal. La manifestación más frecuente es la enfermedad cerebral parenquimatosa. La afectación no parenquimatosa suele presentar hipertensión intracraneal benigna con papiledema, meningitis o trombosis del seno venoso cerebral, con buen pronóstico. ${ }^{6}$

La prevalencia de la enfermedad de neuroBehçet durante la niñez es del $5 \%$ al $15 \%$. La cefalea es el síntoma neurológico más frecuente. Si bien la trombosis venosa cerebral y la parálisis de los pares craneales son frecuentes, la meningitis es relativamente rara. ${ }^{3,7}$ Nuestra paciente tenía cefalea aguda y un cuadro clínico típico de meningitis linfocítica. Los antecedentes clínicos, los análisis bioquímicos y los exámenes instrumentales apuntaban a meningitis. En un principio, la sospecha de origen infeccioso nos llevó a iniciar un tratamiento antiinfeccioso.

No hay criterios diagnósticos o características radiológicas patognomónicas para la EB en la población pediátrica. La RM es la técnica de diagnóstico por imágenes más sensible. En los adultos con neuro-Behçet, en la RM se observan lesiones principalmente en el tronco encefálico, los núcleos basales y la sustancia blanca. En un estudio de la neuro-Behçet parenquimosa en la población pediátrica, los hallazgos más frecuentes de la RM incluyeron lesiones diencefálicas o en el tronco encefálico, ya sea que estén asociadas con el área periventricular o subcortical. ${ }^{8-9} \mathrm{La}$ paquimeningitis es un trastorno meníngeo inflamatorio crónico poco frecuente que se caracteriza por un engrosamiento difuso o localizado de la duramadre, causado por diversas enfermedades infecciosas, autoinmunitarias o malignas. ${ }^{10}$ Si bien hay algunos estudios que describen la paquimeningitis con neuro-Behçet en adultos, no hay ninguno que lo haga en la población pediátrica.

El diagnóstico de neuro-Behçet resulta desafiante para los pediatras; puede generar complicaciones irreversibles. En el caso de nuestra paciente, era muy difícil sospechar de neuroBehçet en un principio. En las primeras pruebas, no hubo mejoría clínica con el tratamiento antibiótico. En los análisis de sangre y LCR, los marcadores de trastornos autoinmunitarios y del tejido conjuntivo y las pruebas tumorales fueron negativos. En las pruebas avanzadas para la detección de meningitis, no se hallaron agentes infecciosos. La anamnesis fue exhaustiva. Para el diagnóstico de neuro-Behçet, se consideraron las úlceras bucales recurrentes, meningitis aséptica $\mathrm{y}$ antecedentes de ataque de artritis. El examen oftalmológico fue normal y la prueba de patergia, negativa. A diferencia de los adultos, en la población pediátrica no es necesaria la prueba de patergia para el diagnóstico. La presencia del alelo HLA-B51 respaldó el diagnóstico. Se observó rápidamente recuperación clínica y radiológica luego del tratamiento con inyecciones intravenosas repetidas de dosis altas de corticoesteroides.

Hasta el momento, el tratamiento de neuro- 
Behçet sigue siendo mayoritariamente empírico. El pronóstico de la enfermedad de neuro-Behçet no parenquimosa es más favorable; aquellas manifestaciones (como la paquimeningitis) se pueden tratar con corticoesteroides como único agente. Se deben combinar los corticoesteroides con inmunodepresores en caso de respuesta refractaria. La recuperación clínica de nuestra paciente fue rápida con los corticoesteroides. ${ }^{11}$

La enfermedad de neuro-Behçet, al igual que otros trastornos sistémicos (infecciosos, autoinmunitarios o por tumores), puede provocar paquimeningitis y meningitis aséptica. En el diagnóstico diferencial del síndrome meníngeo agudo, se debe incluir la EB, a menos que se demuestre la presencia de un agente infeccioso.

En nuestra paciente, el diagnóstico se realizó mediante la exclusión de afecciones más frecuentes y a partir de la excelente respuesta al tratamiento con corticoesteroides. El diagnóstico y el tratamiento tempranos son importantes para minimizar la morbimortalidad.

\section{REFERENCIAS}

1. International Study Group for Bechet's disease. Criteria for diagnosis of Behcet's disease. Lancet. 1990; 335(8697): 1078-80.

2. Koné-Paut I. Behçet's disease in children, an overview. Pediatr Rheumatol Online J. 2016; 14(1):10.

3. Ozen S. Behçet Disease. In Petty R, Laxer R, Lindsley C, Wedderburn L. Textbook of Pediatric Rheumatology. 7th ed. Philadelphia: Saunders. 2016; 40:526-32.

4. Sharma A, De D, Vaiphei K, Dalai R, Ghosh A. Behçet disease in a child: A rare disorder with an unusual complication and favorable outcome. Indian Dermatol Online J. 2018; 9(2):123-5.

5. Maldini C, Lavalley MP, Cheminant M, de Menthon M, Mahr A. Relationships of HLA-B51 or B5 genotype with Behcet's disease clinical characteristics: systematic review and meta-analyses of observational studies. Rheumatology (Oxford). 2012; 51(5):887-900.

6. Uluduz D, Kürtüncü M, Yapici Z, Seyahi E, et al. Clinical characteristics of pediatric-onset neuro- Behçet's disease. Neurology. 2011; 77(21):1900-5

7. Sakakibara R, Koide N, Kishi M, Ogawa E, Shirai K. Aseptic meningitis as the sole manifestation of Behcet's disease. Neurol Sci. 2009; 30(5):405-7.

8. Nanthapisal S, Klein NJ, Ambrose N, Eleftheriou D, Brogan PA. Paediatric Behçet's disease: a UK tertiary centre experience. Clin Rheumatol. 2016; 35(10):2509-16.

9. Mora P, Menozzi C, Orsoni JG, Rubino P, et al. NeuroBehçet's disease in childhood: A focus on the neuro-ophthalmological features. Orphanet J Rare Dis. 2013; 8:18.

10. Yoon BN, Kim SJ, Lim MJ, Han JY, et al. Neuro-Behçet's Disease presenting as Hypertrophic Pachymeningitis. Exp Neurobiol. 2015; 24(3):252-5.

11. UralO, GençE,Demir NA, BalcıB, GençBO. Neuro-Behçet's syndrome presenting with features mimicking acute tuberculous meningitis. Int J Infect Dis. 2009; 13(4):e141-4. 